\title{
An Experimental Study of the Influence of Variable In-Cylinder Flow, Caused by Active Valve Train, on Combustion and Emissions in a Diesel Engine at Low Lambda Operation
}

Henrik W. R. Dembinski

Scania CV AB

Hans-Erik Ångström

$\mathrm{KTH}$

Copyright (๑) 2011 Society of Automotive Engineers of Japan, Inc.

\begin{abstract}
Spray and mixture formation in a compression ignition engine is of paramount importance for diesel combustion. In engine transient operation, when the load increases rapidly, the combustion system needs to handle low lambda $(\lambda)$ operation while avoiding high particle emissions. Single cylinder tests were performed to evaluate the effect of differences in cylinder flow on combustion and emissions at typical low $\lambda$ transient operation. The tests were performed on a heavy duty single cylinder test engine with Lotus Active Valve Train (AVT) controlling the inlet airflow. The required swirl number (SN) and tumble were controlled by applying different inlet valve profiles and opening either both inlet valves or only one or the other. The operating point of interest was extracted from engine transient conditions before the boost pressure was increased and investigated further at steady state conditions. The AVT enabled the resulting SN to be controlled at bottom dead centre (BDC) from $\sim 0.3$ to 6.8 and tumble from $\sim 0.5$ to 4 . The fuel injection pressure was varied from 500 bar up to 2000 bar, with increments of 500 bar, for each SN and tumble setting. No exhaust gas recirculation was used in following tests. GT-POWER was used to calculate SN, tumble, and turbulent intensity with the different valve settings. The input data for the GT-POWER flow calculations were measured in a steady-state flow rig with honeycomb torque measurement. The main conclusion of this study was that the air flow structure in the cylinder, characterized by $\mathrm{SN}$, tumble, and turbulent intensity, has a significant effect on the resulting engine
\end{abstract}

combustion and emissions for the investigated range of fuel injection pressures. By increasing SN above 3, while maintaining tumble at low levels, the engine could be run with richer air/fuel mixtures without further increasing smoke emissions at injection pressures 1000 bar and above. Also, $\mathrm{NO}_{\mathrm{x}}$ emissions decreased at $\lambda$ below 1.3; ignition delay time decreased at higher tumble and turbulent levels; and higher levels of swirl resulted in more rapid combustion, decreasing smoke emissions at injection pressures over 1000 bar. Smoke emissions increase at higher engine speeds (above 1200 rpm) and high SN (above 6). The results of this study demonstrate that the mixing process controlled by in-cylinder flow (swirl and tumble) has a dominant effect on combustion.

\section{INTRODUCTION}

The new Euro 7 emission legislation mandates $\mathrm{NO}_{\mathrm{x}}$ emissions to be reduced to around 230-270 $\mathrm{mg} / \mathrm{kWh}$, while particulate matter (PM) remains at $10 \mathrm{mg} / \mathrm{kWh}$ in WHSC (World Harmonized Stationary Cycle) and WHTC (World Harmonized Transient Cycle) tests. As a result, the emissions of $\mathrm{NO}_{\mathrm{x}}$ and $\mathrm{PM}$, generated during transient engine operating conditions, become more and more important.

Significant work has been done on the engine control system to reduce PM emissions during engine transient conditions, when there is a lack of air before the turbo pressure has reached steady state conditions. Different models are implemented in the engine control system to 
predict the oxygen trapped in the cylinder allowing the right amount of fuel to be added each cycle during the transient. As shown in examples of control system models [1],[2],[3],[4], the $\lambda$ cannot pass below a critical value, typically $\lambda$ 1.25-1.30 for an engine without a diesel particle filter, before smoke emissions increase rapidly, thus also increasing transient response time. If the combustion system can maintain low emissions of $\mathrm{PM}$ and $\mathrm{NO}_{\mathrm{x}}$ at a lower $\lambda$ by increasing the amount of fuel during the beginning of the transient, the available exhaust energy and engine torque will be increased, resulting in faster buid up of boost pressure. This can also be traded against lower emissions during the transient. With a variable valve train it is possible to control SN (Eq 1), and tumble (Eq 2) during a transient. Variable valve train is in production in light duty engines, [5], but is not yet common in heavy duty diesels, although research and development is in progress [6]. Port designs on diesel engines have historically been very important [7], [8]. SN has been an important factor in good combustion and low smoke. Recently, research on the injection system using higher injection pressure and exhaust gas recirculation has shown significantly decreased emissions. Although SN has a demonstrable effect on emissions and combustion [9], it has not changed appreciably until today's high injection pressures. Today, some manufacturers have nearly no swirl in their combustion systems.

$$
\begin{aligned}
& S N=\frac{\omega_{\text {Swirl }}}{\omega_{\text {Engine }}} \\
& \text { Tumble }=\frac{\omega_{\text {tumble }}}{\omega_{\text {Engine }}} \\
& \omega_{\text {Swirl }}=\text { Air rotational speed around cy linder vertical centre axis } \\
& \omega_{\text {tumble }}=\text { Air rotational speed around cylinder horisiontal centre axis } \\
& \omega_{\text {Engine }}=\text { Engine rotational crank shaft speed }
\end{aligned}
$$

Normalized Turbulent Intensity $=\frac{u^{\prime}}{V_{p}}$

$u^{\prime}=$ Turbulent intesity $(\mathrm{m} / \mathrm{s})$, calculated by a $\mathrm{k}-\varepsilon$ model

$V_{p}=$ Mean velocity of the piston $(\mathrm{m} / \mathrm{s})$

The aim of this study was to examine engine performance, combustion, emissions, and smoke levels at low $\lambda$ engine transient operating conditions before the boost pressure has reached steady-state operating levels. No changes to engine geometry, apart from an AVT system and extra vanes installed in the valve seat (to enable high SN), were introduced in this study. The influence of air flow on the combustion process was investigated for different levels of $\mathrm{SN}$, tumble, and turbulent intensity, using the AVT system. The influence of fuel injection on combustion was investigated by varying the fuel injection pressure from 500 to 2000 bar, by increments of 500 GT-POWER was used to calculate the swirl, tumble, and turbulent intensity as a function of crank angle degree (CAD) and mean values at BDC, defined in Eq 3, at different valve profile settings. Input data was measured using steady-state flow rig measurements. The test point of interest at engine transient conditions was selected from a measured engine load curve, during which load changes from low to full were made as quickly as possible, Figure 1. The operating points were extracted from engine transient conditions and investigated further at steady-state conditions in a single cylinder test engine. By this method the transient point was able to be studied and modified in a controlled way. The single cylinder engine test boundary conditions are summarized in Table 1. In Figure 1, the tested load point 1 in this study is marked where the maximal engine load at natural aspirated engine operation is possible with normal valve profiles. The injection pressure was varied from 500 bar to 2000 bar by 500 bar increments. The $\lambda$ was kept constant at 1.25 for injection pressures up to 1500 bar by changing the boost pressure for different valve strategies. The fuel quantity per engine cycle was kept constant for all test cases (from 500 to 1500 bar injection pressures) by changing the ontime on the fuel injector. IMEP is changing a bit due to for example different pumping work with different valve strategies. When the injection pressure rises, the $\lambda$ can be further decreased without high smoke and the 2000 bar case was set to a constant $\lambda$ of 1.2 . To maintain a constant $\lambda$ when the valve profiles were changed, the boost pressure was influenced to keep the air mass constant in the cylinder, in the same way as in the cases with lower injection pressures.

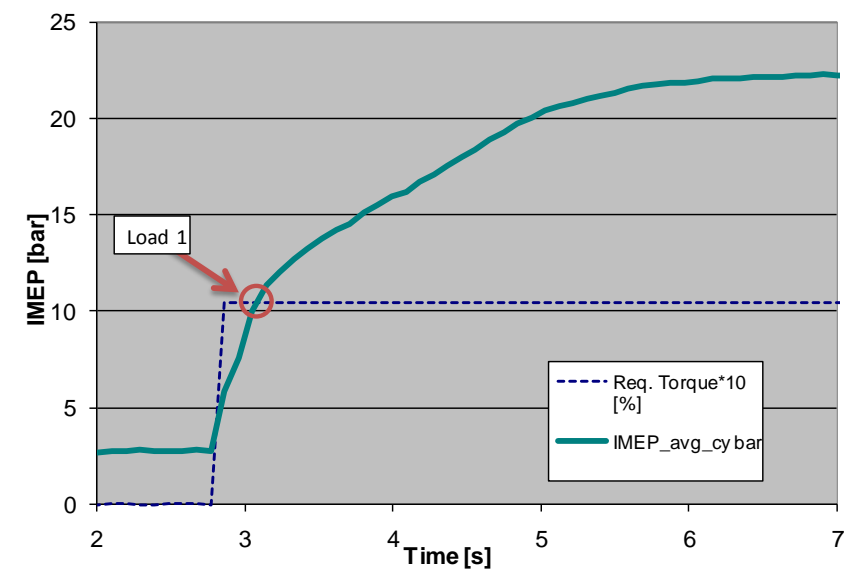

Figure 1 Engine load buildup during a transient at 1000 rpm constant engine speed, from low load ( $3 \mathrm{bar}$ ) IMEP to fullload (23 bar) IMEP. Dashed line is requested engine torque.

To understand the emission behaviour from very 
low to high load, test point 2 Table 1 , was set up with constant air mass flow and the injected fuel mass (and therefore the $\lambda$ ) was varied. Two different valve strategies, giving low and high SN, were tested to discover at what $\lambda$ soot reduction occurs for the different SN.

The swirling air speed in the cylinder is directly dependent on engine speed when SN is constant at different engine speeds. The spray and air interaction is time dependent. To examine the effects on combustion, test point 3 was set up with an engine speed sweep from 800 to 2000 rpm and two valve settings, giving high and low SN.

Table 1. The tested load cases with boundary conditions

\begin{tabular}{|c|c|c|c|}
\hline & Load 1 a,b,c,d & Load 2 & Load 3 \\
\hline Rail press. [bar] & $500,1000,1500 \& 2000$ & 2000 & 1500 \\
\hline Speed [rpm] & 1000 & 1000 & $800-2000$ \\
\hline Swirl number & $0.4-6.7$ & $3.4 \& 6.1$ & $3.4 \& 6.1$ \\
\hline Tumble & $0.5-4$ & $1.1 \& 2.5$ & $1.1 \& 2.5$ \\
\hline Lambda & $1.2-1.25$ & $8-0.99$ & 1.25 \\
\hline Inlet press. Rel. [bar] & $0.09-0.17$ & 0.5 & $0.12-0.20$ \\
\hline SOI ['ATDC] & $-11,-6,-4,-3$ & -2 & -14 to -2 \\
\hline IMEP [bar] & $\sim 10$ & $1.2-15.5$ & $\sim 9.5$ \\
\hline
\end{tabular}

\section{TEST SETUP}

The single cylinder test engine used in this study was based on Scania D12 geometry, updated to conform to Euro 5 legislation, with an injection system capable of 2500 bar (Table 2). The cylinder head was fitted with a Lotus AVT system to allow different valve profile setups for different air flow characteristics.

Table 2 Engine specifications

\begin{tabular}{|l|l|}
\hline Test engine & 4 -stroke Scania D12 single cyl \\
\hline Bore/stroke [mm] & $127 / 154$ \\
\hline Connecting rod [mm] & 255 \\
\hline Compression ratio & $17.3: 1$ \\
\hline No. of valves & 4 \\
\hline Valve actuation system & Lotus AVT \\
\hline Injection system & Scania common rail XPI \\
\hline Injector holes & 8 \\
\hline $\begin{array}{l}\text { Spray angle [deg] } \\
\text { (between cyl. head and spray) }\end{array}$ & 16 \\
\hline Max inj pressure [bar] & 2500 \\
\hline
\end{tabular}

The cylinder head, seen in Figure 2, had two separate inlet channels (indicated with blue lines) with extra masking over the valve seat (red rings in Figure 2b). The masking over the valve seat was used to generate higher SN. The SN could then be lowered by reducing the lift height of the valve, enable a wider range of $\mathrm{SN}$ to be reached.

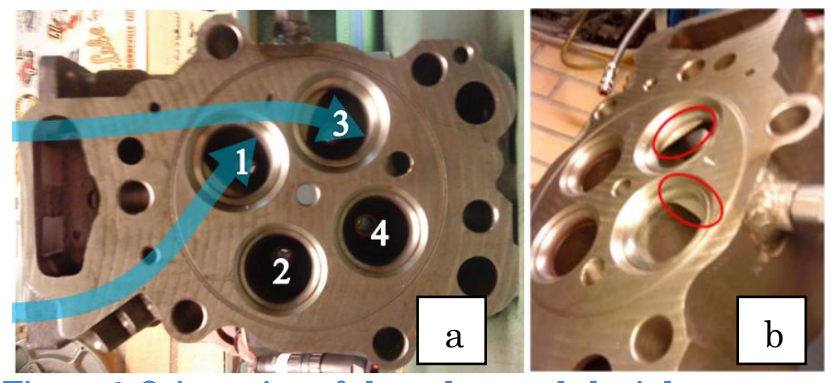

Figure 2 Orientation of the valves and the inlet ports on the tested cylinder head. The inlet valve seats have extra masking, marked in picture $b$, to increase SN.

The AVT is a hydraulic system that drives the valves with hydraulic pressure (see Figure 3). The system uses servo valves to control the hydraulic pressure and the engine valve movement. One double-acting hydraulic actuator per valve is mounted on the cylinder head. Coaxial with the actuator, a hydraulic piston is mounted on top of a standard poppet valve. To accurately record the position of the valve a displacement transducer is placed on top of the piston. A hydraulic pump and an oil conditioning system deliver the high pressure oil to the actuator valves. More information about the AVT system can be seen in [10].
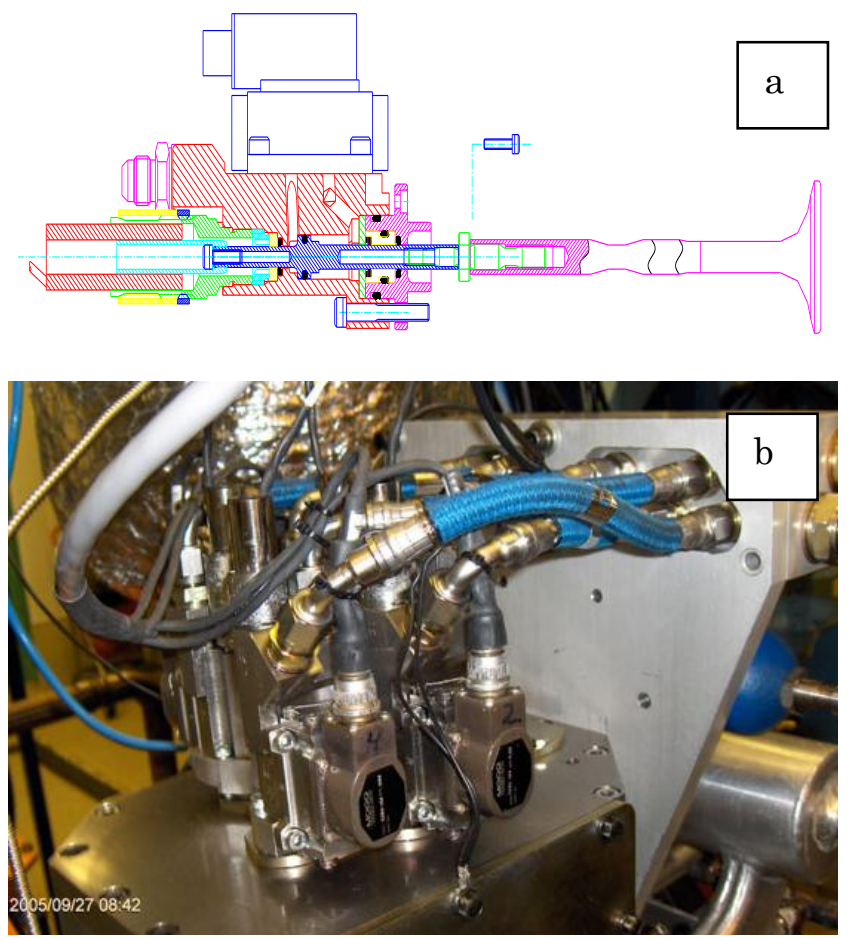

Figure 3 The Lotus AVT valve actuator with inlet valve (a) and the actuators on the cylinder head (b).

The AVT system allowed control of the valve opening profile, duration, lift height, acceleration, etc. Matlab was used to generate the tested valve profiles. The exhaust back pressure was set equal to the inlet pressure (1:1), if nothing else is mentioned. The cooling water and oil temperatures were stabilized at $90^{\circ} \mathrm{C}$. Start of injection (SOI) used in this report is the start of the electrical signal sent to the Scania XPI 
common rail injector. The SOI delay and end of injection between electrical signal and the fuel injection is different depending on injection pressure. For more details, see [11]. Cylinder pressure measurements were taken with an AVL 12QP505CLK piezo transducer with a range up to 250 bar. The signal was logged with a resolution of $0.1 \mathrm{CAD}$ and 100 cycles per measuring point. AVL smoke meter type 415 was used for smoke measurements and the result displayed as filter smoke number (FSN). Emission measurements were taken with a Horiba EXSA-1500.

\section{STEADY STATE FLOW RIG}

The tested cylinder head was measured in a steady-state flow rig to characterize the swirling and tumbling flow. By measuring the torque on the honeycomb at different valve lifts and constant pressure drop over the valves of 25 mbar, the resulting SN was calculated both in GT-POWER and by the Thien method [12]. Tumble was measured in the same rig, but the cylinder head was mounted on a liner with a 90 degree L-type adaptor to enable tumble measurement in the swirl rig (see [13]). Swirl and tumble were measured separately and together for both inlet valves. When the cylinder head has both swirl and tumble, the tumble can be difficult to measure. In [14], different valve profiles effects on in cylinder flow have been modeled in KIVA computational fluid dynamics code. The tumble created during the inlet stroke was found to change the flow angle during the inlet stroke., The SN changes with different valve lifts, as does the angle where the tumble is tangential to the measuring axis in the steady state flow rig. The cylinder head angle therefore needs to be adjusted to maintain tangential flow. The cylinder head was measured every 5 degrees for valve lift $1-15 \mathrm{~mm}$ with increments of $1 \mathrm{~mm}$. Figure 4 shows the measurements for one valve, the straight port. The highest mean tumbles during a standard lift valve profile were chosen for the data set marked p70, used in the following calculations for Table 3 and Table 4 .

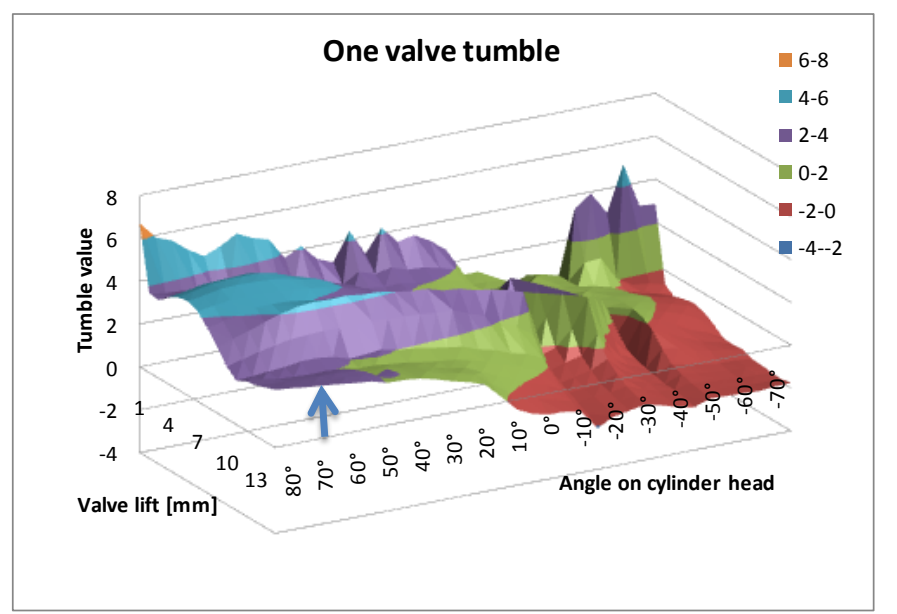

Figure 4 Tumble for the straight port with valve lift on

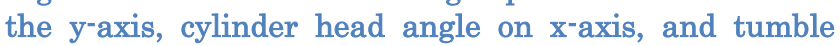
number on $\mathrm{z}^{-a x i s .}$

\section{CALCULATIONS AND SIMULATIONS}

The airflow parameters, SN, tumble, and turbulent intensity were evaluated using the results obtained from measurements performed in the steady-state flow rig. Two methods, the engine simulation program GT-POWER and the Thien method [12], were used to calculate SN in order to compare them. In Table 3 (one valve operation) and Table 4 (two valve operation) the calculated SN (Thien method and GT-POWER method), tumble, and normalized turbulent intensity for the valve profiles, seen in Figure 5, are shown for load case 1 . The normalized turbulent intensity is a global mean parameter for the entire cylinder and values shown in the tables are at cycle start 100 CAD before top dead centre (TDC), calculated in GT-POWER with a $\mathrm{k}-\varepsilon$ model. The two methods for evaluation of SN, GT-POWER and Thien, differ in results, especially at high SN and for any valve profile that differ muchs from standard. The reason for this can be seen in how the SN is calculated by each method (see [15], [16], and [17] for how GT-POWER calculates air flow). Thien uses the movement of the piston to estimate the air volume passing the inlet valve, assuming incompressible flow over the valve during the entire inlet stroke. The dz/da term in Eq 4 is the volume change depending on $\mathrm{CAD}$. $\mathrm{Eq} 5$ is the swirl coefficient definition for Thien and Eq 6 is that for GT-POWER. This means that in the Thien definition swirl can only be generated when the piston moves down, although the inlet valves are open before and after TDC and BDC (see [12]). The inertia in the inlet system with the pulsating flow is not taken into account either in the Thien method. Both GT-POWER and Thien assume solid body motion in the cylinder. PIV measurements ([18], [19]), however, have shown that this is not the case in a real engine. GT-POWER calculates the air mass flow passing 
into the cylinder depending on the pulsating pressure in the inlet system, the cylinder, and the valve profile. With the calculated air flow, the momentum contribution from the air flow moving into the cylinder is added to the rotating air mass in the cylinder. The tumble algorithm in GT-POWER is quite similar to the calculation method for swirl and is shown in detail in [15].

$$
\begin{aligned}
& S N_{T}=\pi \cdot \int N(\alpha) \cdot\left(\frac{d}{d}\right) \\
& N(\alpha)=2 \cdot s \cdot \frac{M \cdot \rho_{2}}{q^{2}}
\end{aligned}
$$

$s=$ Stroke, $M=$ Torque, $\rho_{2}=$ Air density, $q=$ volume flow

$C_{S}=\frac{M}{\dot{m} \cdot V_{i s} \cdot B / 2}$

$M=$ Torque, $\dot{m}=$ Air mass flow, $\mathrm{V}_{\text {is }}=$ Isentropicair flow (throu vale), $B=$ cyl.bore

Table 3 SN, tumble, and normalized turbulent intensity for one valve operation at load case 1 .

\begin{tabular}{|c|c|c|c|c|}
\hline $\begin{array}{c}\text { One valve } \\
\text { (straight } \\
\text { channel) }\end{array}$ & $\begin{array}{l}\text { SN } \\
\text { (GT) }\end{array}$ & $\begin{array}{c}\text { SNT } \\
\text { (Thien) }\end{array}$ & $\begin{array}{c}\text { Tumble } \\
\text { (GT) }\end{array}$ & $\begin{array}{c}\text { Norm. } \\
\text { Turbulent } \\
\text { intensity at } \\
\text { cycle start (GT) }\end{array}$ \\
\hline $15 \mathrm{~mm}$ std & 6.11 & 6.80 & 2.52 & 1.70 \\
\hline $10 \mathrm{~mm}$ std & 5.05 & 5.37 & 3.35 & 1.77 \\
\hline $5 \mathrm{~mm} \mathrm{std}$ & 2.12 & 1.95 & 4.00 & 2.09 \\
\hline $15 \mathrm{~mm}$ step & 6.67 & 7.69 & 2.39 & 1.67 \\
\hline $10 \mathrm{~mm}$ step & 5.73 & 6.46 & 2.67 & 1.71 \\
\hline $5 \mathrm{~mm}$ step & 2.47 & 2.78 & 3.87 & 1.88 \\
\hline
\end{tabular}

Table 4 SN, Tumble and normalized turbulent intensity for two valves at load case 1 .

\begin{tabular}{c|c|c|c|c} 
& SN & $\begin{array}{c}\text { SNT } \\
\text { Two valves }\end{array}$ & $\begin{array}{c}\text { Norm. } \\
\text { Tumble } \\
\text { (GT) }\end{array}$ & $\begin{array}{c}\text { Nurbulent } \\
\text { (Thien) } \\
\text { intensity at } \\
\text { cycle start (GT) }\end{array}$ \\
\cline { 1 - 1 } $15 \mathrm{~mm}$ std & 3.35 & 3.49 & 1.11 & 1.40 \\
\cline { 1 - 1 } $10 \mathrm{~mm}$ std & 2.53 & 2.52 & 0.87 & 1.47 \\
\cline { 1 - 1 } $5 \mathrm{~mm}$ std & 0.43 & 0.35 & -0.72 & 1.69 \\
\cline { 1 - 1 } $15 \mathrm{~mm}$ step & 3.80 & 4.10 & 1.33 & 1.38 \\
\cline { 1 - 1 } $10 \mathrm{~mm}$ step & 3.16 & 3.38 & 1.11 & 1.43 \\
\cline { 1 - 1 } $5 \mathrm{~mm}$ step & 0.70 & 0.63 & -0.52 & 1.60
\end{tabular}

The valve profiles tested in this study are shown in Figure 5. The valve profiles marked 'std' have the normal shape with moderate valve acceleration. Profiles marked 'step' have a trapezoid shape and the fastest opening and closing acceleration that the AVT system admits at $1900 \mathrm{rpm}$. Equal inlet valve opening (IVO) CAD and duration were used in all cases as seen in Figure 5. The lift height was varied from $5 \mathrm{~mm}$ to $15 \mathrm{~mm}$ in increments of $5 \mathrm{~mm}$ for all tested valve profiles.

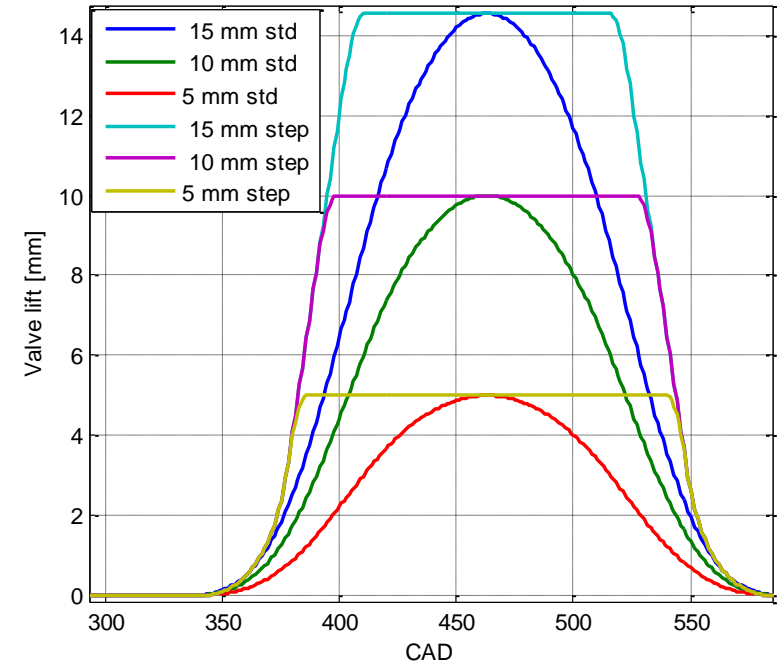

Figure 5. The tested valve profiles. The dark blue profile is the standard valve profile used in the standard engine.

$\mathrm{SN}$, tumble, and turbulent intensity were evaluated using GT-POWER. The results for two valves at $15 \mathrm{~mm}$ lift at std valve profile were plotted for the entire engine cycle, as shown in Figure 6. During the intake stroke the swirl and tumble builds up. Their values depend on valve lift. At inlet valve close (IVC), the tumble and swirling motions are conserved in the cylinder. The air flow speed accelerates during compression due to the geometric change. The turbulent intensity is high during the inlet stroke when the air flows into the cylinder at high velocity. The turbulent intensity drops during compression and at TDC it starts to increase again when the tumble motion breaks into turbulence with a smaller length scale. This has also been observed in LES simulations in [20]. At TDC the fuel injection creates high turbulent intensity in the cylinder, as shown in Figure 6 . The turbulent intensity created by the injection is not modelled with the tested injection pressures. It should only be seen as a rough estimate.

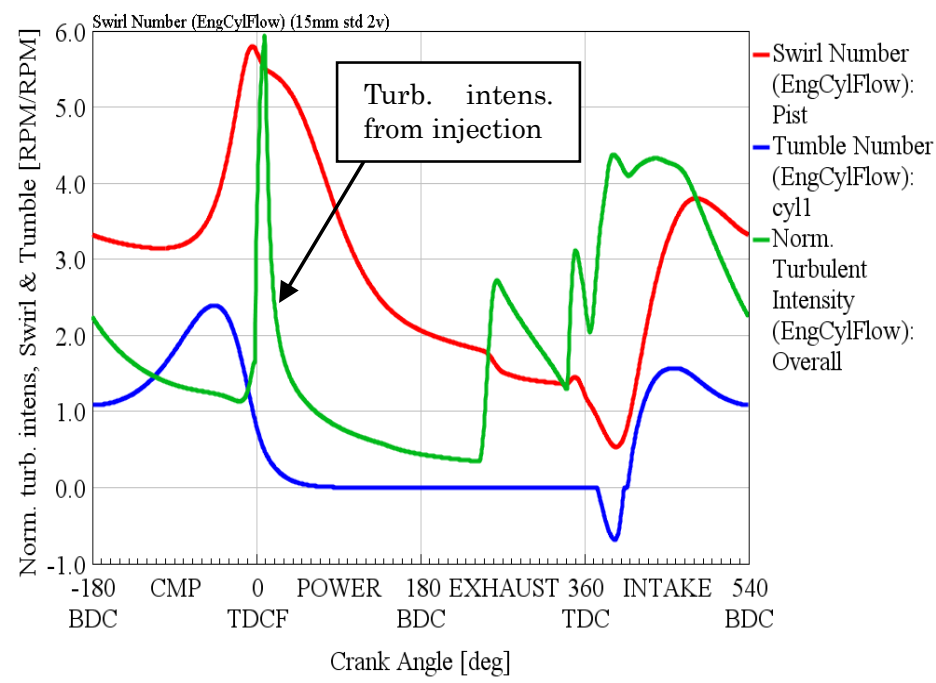


Figure 6 The swirl, tumble and normalized turbulent intensity plotted for the entire engine cycle.

In Figure 7, swirl is shown versus crank angle for two valves and in Figure 8 for one valve. The valve lift varied between 5 and $15 \mathrm{~mm}$ in increments of $5 \mathrm{~mm}$ with the same air flow in all cases. At the intake stroke the swirl is accelerated and dependent on valve lift. Higher lift gives increased swirl on the cylinder head. During the compression stroke when the piston moves up, the swirl accelerates as the air is centred in the piston bowl, which has a smaller radius than the cylinder liner. The rotating air speed is reduced by the skin layer friction nearest the walls. Close to TDC, the smaller radius, the simplified solid body rotation model gives nearly the same angular momentum as when the inlet valve is closed. This can lead to a significant increase in rotational speed. During the power stroke, the swirl starts to decrease as the piston moves down. Approximately half of the $\mathrm{SN}$ at BDC before the compression stroke is conserved until the exhaust valve opens. The higher $\mathrm{SN}$ in one valve versus two valves may be explained by the fact that twice the air needs to be handled of one single port. The air therefore needs to complete more revolutions in the cylinder before the same amount of air has entered the cylinder by one valve than by the two valves.

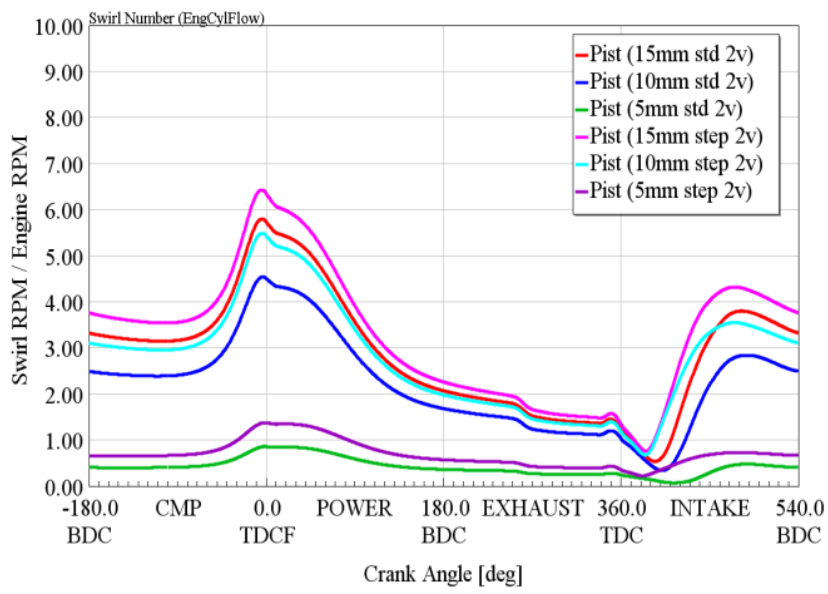

Figure 7 Swirl level, estimated with GT-POWER, for the entire engine cycle, using two valves for the inlet.

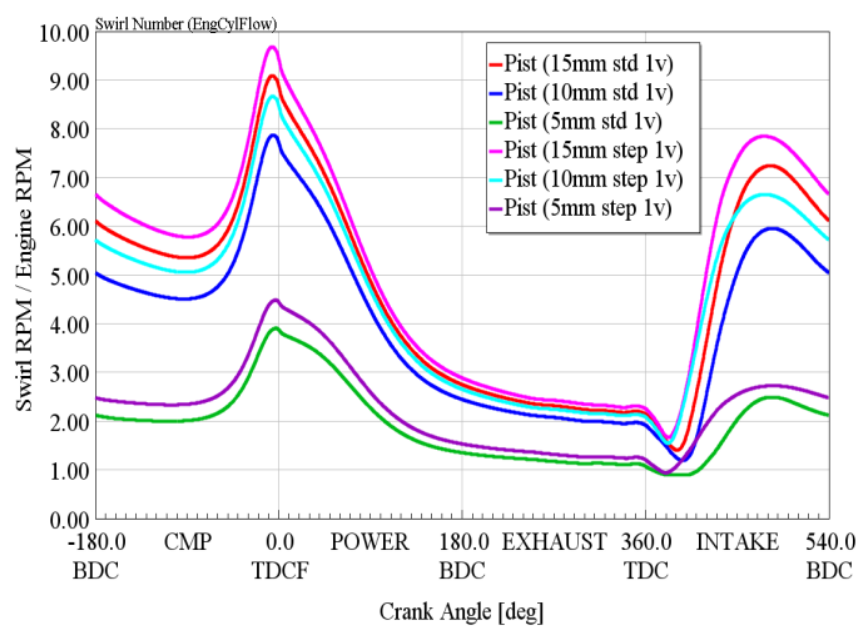

Figure 8 Swirl, estimated with GT-POWER, for the entire engine cycle, using one valve.

The results in Figure 9 and Figure 10 show that the tumble flow was higher when only one valve was used than when two valves were. The reason for the higher tumble is partly explained by the same reason for the higher SN, one port needs to handle twice as much air. The other reason is that the second closed valve that has no effect on the airflow and the off-centredness of the open valve strengthens the tumble effect. Tumble breaks down during compression to small scale turbulence as seen in the figures and also shown in [20]. The tumble seems to change direction in the two-valve case when high valve lift is used (see Figure 9). At close to $6-7 \mathrm{~mm}$ valve lift, the tumble flow changes from negative to positive values. This was clearly observed also in the steady-state flow rig (not shown in this paper).

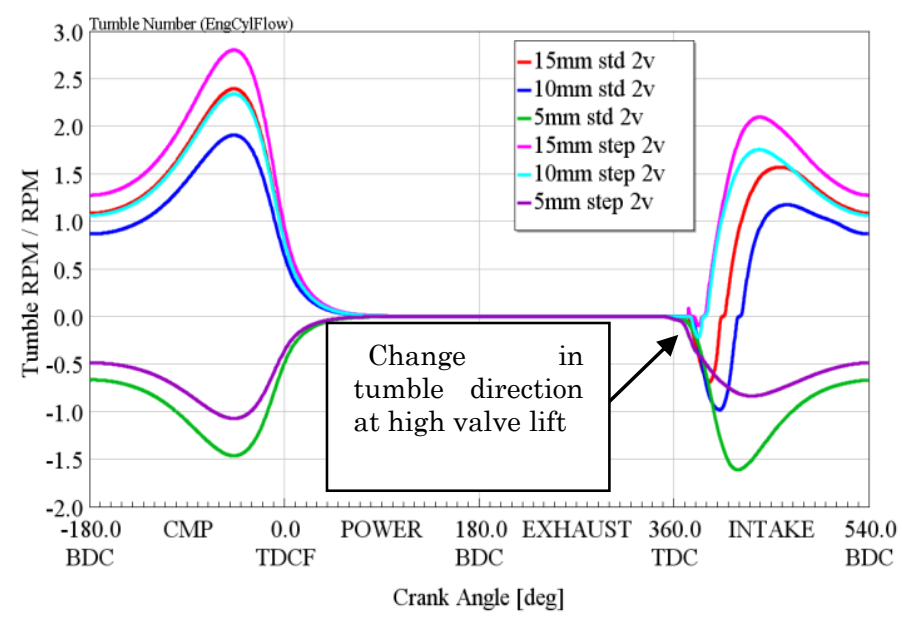

Figure 9 Tumble, estimated with GT-POWER, for the entire engine cycle, using two valves for the inlet. 


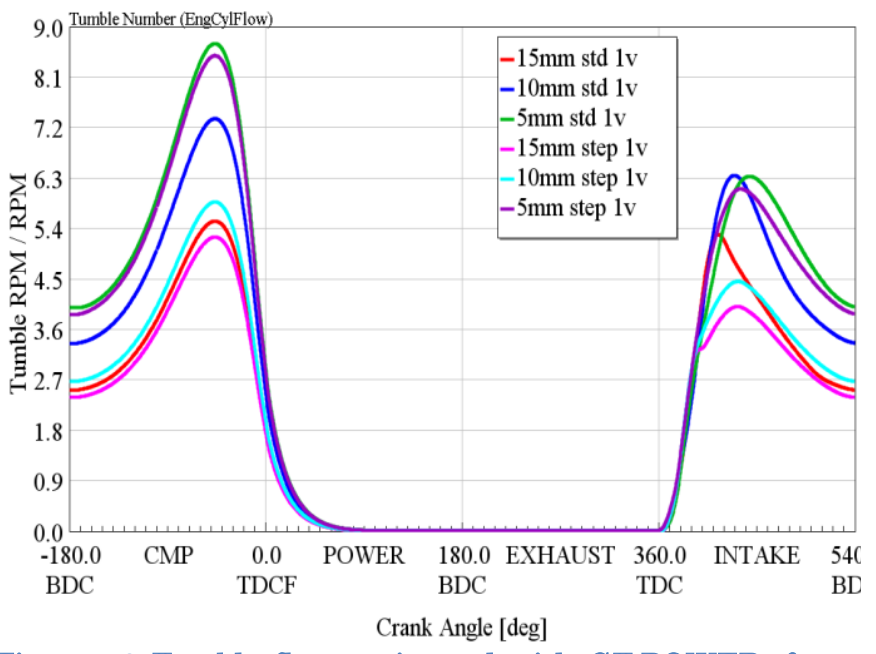

Figure 10 Tumble flow, estimated with GT-POWER, for the entire engine cycle, single valve for the inlet.

The turbulent intensity during the inlet stroke was higher when one valve was used, due to higher inlet velocities, as presented in Figure 11 (one valve) and Figure 12 (two valves). The figures' X-scales are plotted for the inlet and beginning of the compression stroke. Turbulent intensity increases when low or limited valve lift is used. The turbulent intensity decreases quickly after IVC and the reason is that the biggest turbulence length scale dissipates rapidly when the source of turbulence production is shut down. When the turbulence length scale is the same as the viscous length scale, the turbulence ceases.

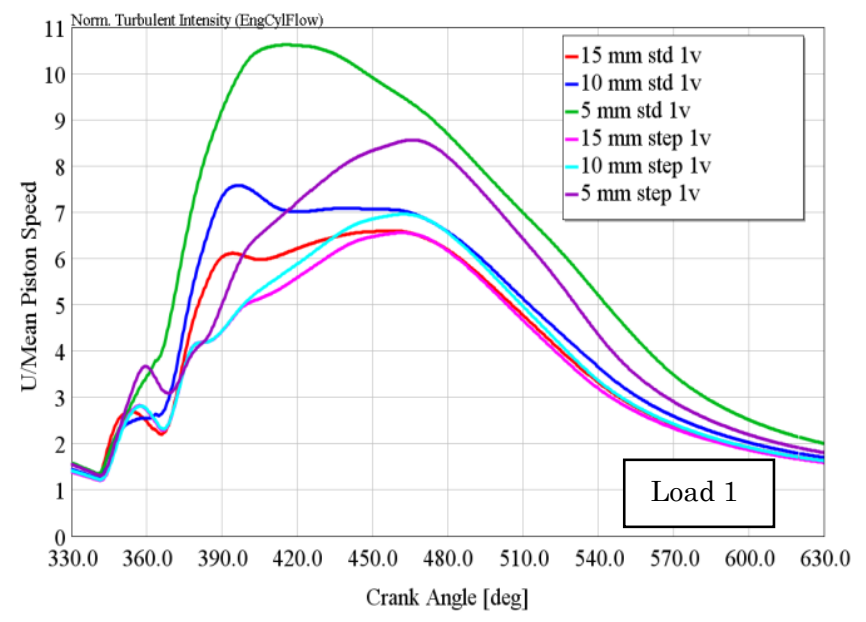

Figure 11 Turbulent intensity estimated with GT-POWER for the inlet stroke, using one valve.

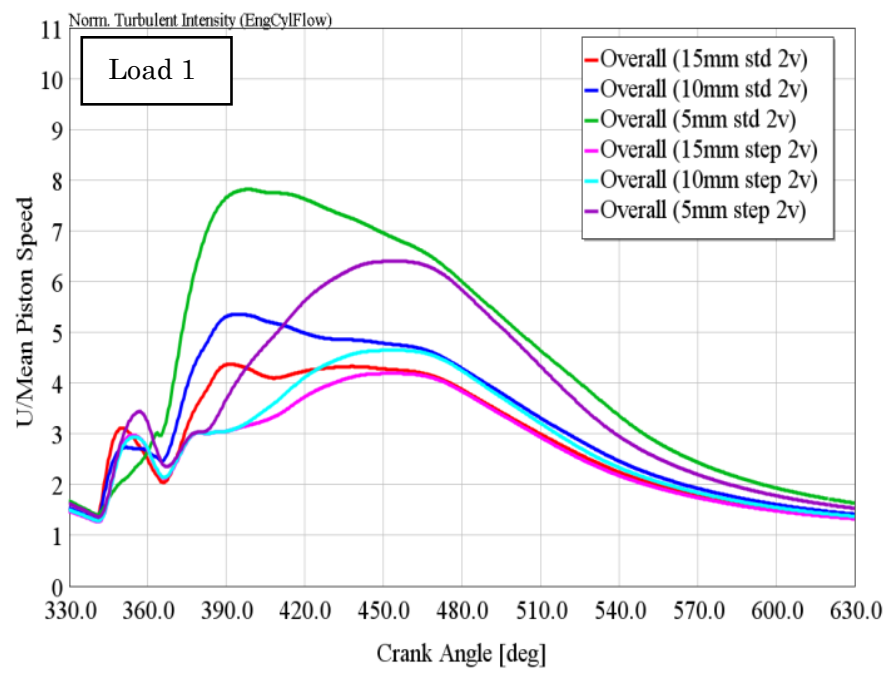

Figure 12 Turbulent intensity estimated with GT-POWER for the inlet stroke, using two valves.

\section{SINGLE CYLINDER ENGINE TEST}

The heat release (HR) was affected at all tested injection pressures when the $\mathrm{SN}$ was changed, as shown in Figure 13 for load point 1. The crank angle at maximum cylinder pressure (APmax) was set to $11^{\circ}$ after TDC by adjusting SOI at all tested injection pressures. Increased injection pressure gives shorter and higher amplitude of HR for the same amount of fuel injected into the cylinder. Increased injection pressure increases the turbulent intensity and gives longer penetration of the spray in the combustion chamber, [21]. The induced turbulent intensity at inlet stroke does not have an effect on the HR. As seen in the GT-POWER simulations, the only air flow that survives the whole power stroke is the swirl. When the SN increases from 0.4 to 6.7 (lowest and highest tested SN), the diffusion combustion rate increases in amplitude and the after-oxidation rate decreases (see green arrows in Figure 13). The same trend is observed for all injection pressures. When the other tested valve profiles are plotted on the same graph, the $\mathrm{SN}$ is the dominant effect influencing the shape of HR. SN values between 0.4 and 6.7 appear between the two lines with the highest and lowest tested SN. 


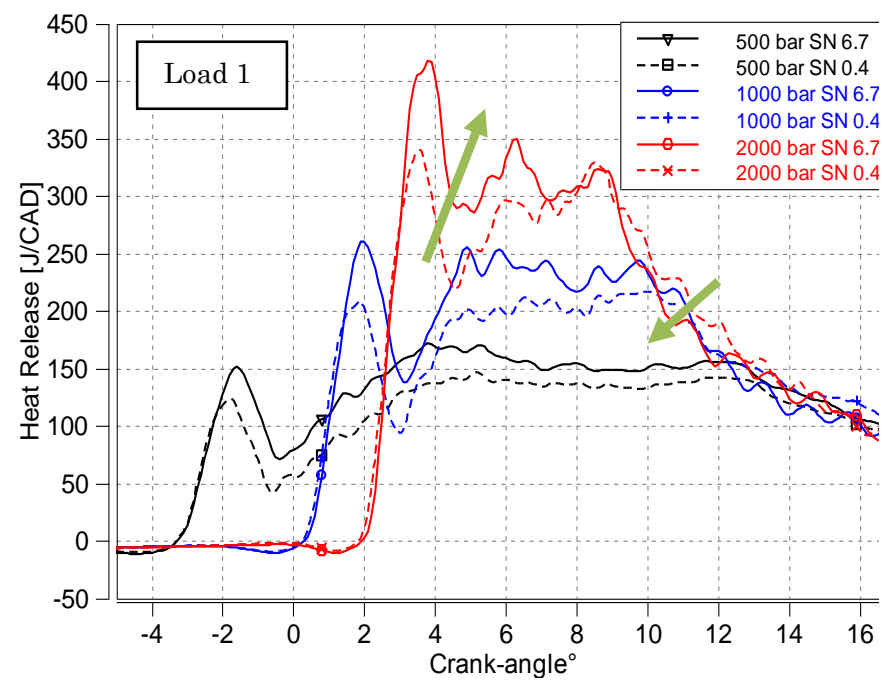

Figure $13 \mathrm{HR}$ for load point 1 at different injection pressures and SN. The arrows shows the HR change when increasing SN.

\section{IGNITION DELAY}

The turbulent intensity, normalized with mean piston velocity at 100 CAD before TDC (generated by the inlet valves) for the tested valve setups is plotted with swirl and tumble in Figure 14. The tested valve profiles are marked in the graph with triangles for one-valve tests and circles for two-valve tests. The colour scale shows the turbulent intensity between the isolines in the graph. The values of SN, tumble, and turbulent intensity can also be seen in Table 3 and Table 4. When one valve is used the turbulent intensity is higher than when two valves are used, and at $5 \mathrm{~mm}$ lift height with std valve profile the highest turbulent intensity is observed due to the high air speed over the valve seat. In [22], [23], [24], and [25] it was reported that the turbulent intensity from the inlet port influenced combustion with shorter combustion periods, shorter ignition delays, and lower emissions. In the data presented in this paper, the trend of decreasing ignition delay is more associated with tumble, and soot emissions are more associated with SN.

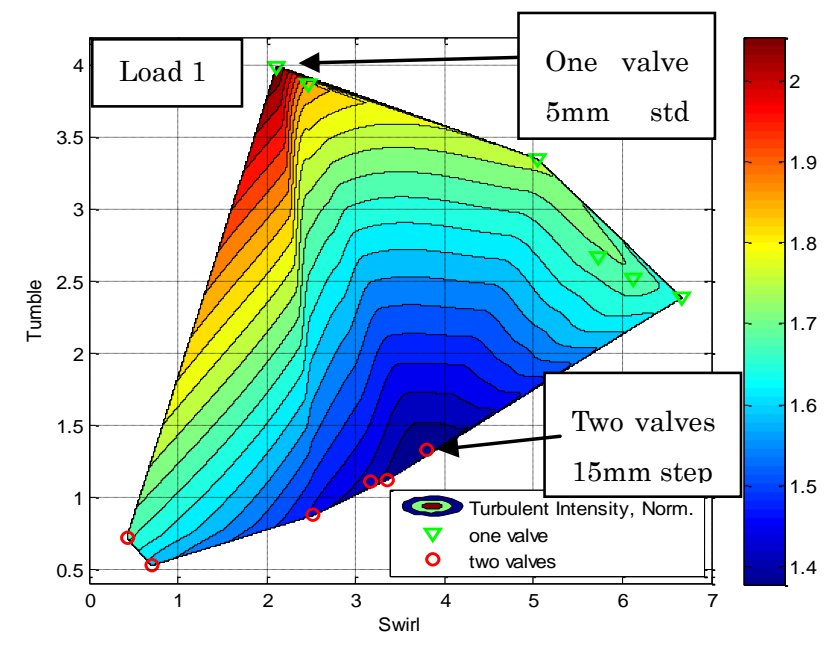

Figure 14 Turbulent intensity, versus swirl and tumble at 100 CAD before TDC combustion.

The ignition delay with 1000 bar injection pressure is plotted versus $\mathrm{SN}$ and tumble in Figure 15. The ignition delay is defined as the time between the fuel injection start and positive HR. The red areas show short ignition delay and the blue areas shows long ignition delay. Both the shortest and longest ignition delay can be observed at a constant SN (see the black arrow in Figure 15). Tumble and turbulent intensity seem to affect ignition delay (Compare Figure 15 with Figure 14, where the air flow influences are shown for tested valve settings). Higher SN should give a longer ignition delay, caused by the higher heat transfer during compression and resulting lower compression temperature, but that seems not to be the dominating factor.

The ignition delay is short in the region where the turbulent intensity is high. The turbulent intensity created from the inlet valves during inlet stroke however does not survive to combustion, as shown in the GT-POWER simulations in Figure 6, its transformed to heat when it breaks down. With higher turbulent intensity, the heat transfer increases from cylinder head, liner, and hot valves to the inlet air under the inlet stroke. Typically are the inlet valve temperature round 300 to $400^{\circ} \mathrm{C}$. A higher initial temperature in the cylinder at IVC gives a higher compression temperature and thereby a shorter ignition delay. Calculations on ignition delay with Arrhenius correlation may be found, for example, in [26]. Using measured cylinder pressure cannot alone explain the difference in ignition delay. The measured ignition values range from $1.9 \mathrm{CAD}$ to $2.6 \mathrm{CAD}$ compared with 2.04 CAD to $2.12 \mathrm{CAD}$ in the calculated case (calc. with the Arrhenius correlation). This means that the ignition delay is affected not only by pressure and temperature, but also by the air flow in the cylinder.

To minimize the effect of heat transfer 
from the engine to the inlet air during the inlet stroke, and thereby to control the start temperature before compression, single combustion tests were performed. The inlet pressure was set to the same level as in the standard case, but the inlet-, engine- and oil-temperatures were all set to $40^{\circ} \mathrm{C}$. The engine was motored without injection or combustion except for one engine cycle. The heating of the engine was thereby kept to a minimum. Three measurements were done at every test point with 3 minutes of motoring (without combustion) between the measurements. A mean value was calculated for every test case and plotted in Figure 16. The ignition delay, however, is affected in the same way as the standard case shown in Figure 15, and the difference increases compared with the standard case. The SN seems not to affect the ignition delay appreciably. Turbulent intensity created during the inlet stroke gives a higher heat transfer during the inlet stroke but does not seem to be the only dominant influence on ignition delay. Higher tumble though seems to affect the start of combustion. When the piston is near TDC the global tumble flow is transformed to small-scale turbulent vortexes, as shown previously when the combustion chamber geometry changes. This is of paramount importance for the turbulent combustion that occurs in an SI engine. In a diesel engine the first added fuel burns premixed. If the turbulence is increased during the ignition delay, the rate of heat and of active species through the pre-ignition and reaction zones is also increased [27]. This means that the mixing process of air and fuel is more intensive and the reaction time decreases with ignition delay time. This together with higher compression temperature created by the higher turbulent intencity (from low lifting inlet valves) gives a shorter ignition delay compare to the standad valve profile case, see figure 15 .

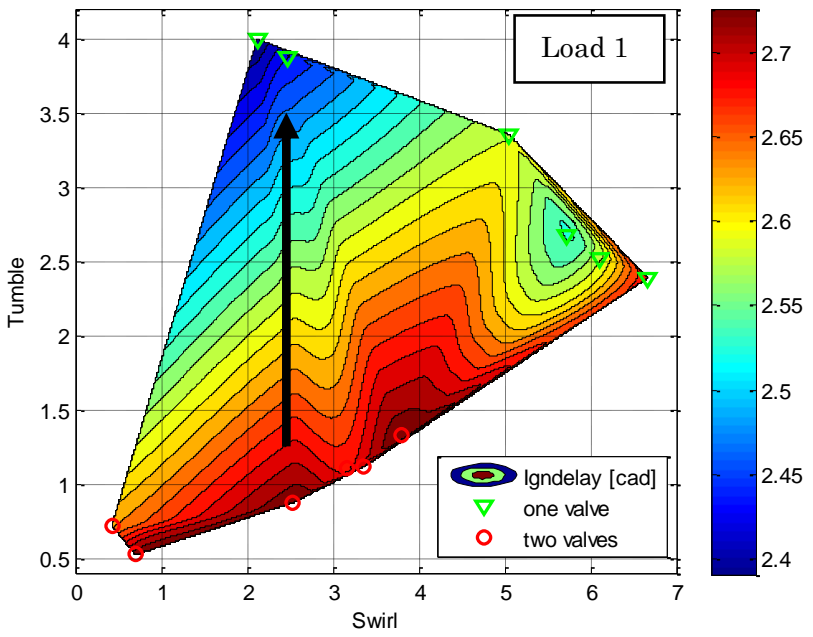

Figure 15 Ignition delay for load $1 \mathrm{~b}$ at 1000 bar injection pressure.

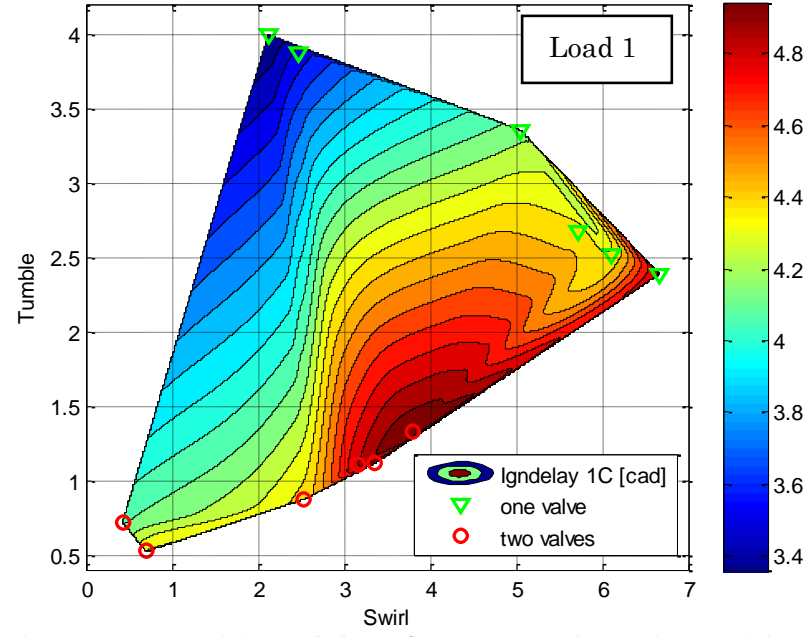

Figure 16 Ignition delay for motored engine without combustion except for one single engine cycle.

\section{EMISSIONS}

At load point 1, the injection pressure was varied from 500 bar to 2000 bar and $\lambda$ was kept constant at 1.25 for injection pressures up to 1500 bar. For 2000 bar, $\lambda$ was set to 1.20 . SN and tumble imposed into the airflow by the AVT was varied as shown in Table 1. With high injection pressures the soot emissions decrease, allowing room to increase the amount of fuel and the possible engine load for a certain amount of air trapped in the cylinder. At low soot emissions, however, it is hard to measure small differences with accuracy. With higher injection pressures, smoke emissions decrease and $\mathrm{NO}_{\mathrm{x}}$ increase, as in the classic $\mathrm{NO}_{\mathrm{x}} /$ soot trade-off curve. In Figure 17 the smoke emissions are plotted for different SN and tumble at load point 1 . The smoke emissions are marked by colour, with blue representing low emissions and red high emissions. Observe that the colour bar scales are different between the graphs. The different valve settings are also marked on the graphs with a triangle for one valve and a circle for two valves. At 500 bar injection pressure, the lowest smoke emissions are seen between SN 2 and SN 3.5 at low tumble. At both higher and lower SN the smoke increases. At 1000 bar, the area with low smoke increases and moves to higher SN. At SN under 3 , soot emissions start to increase. The black arrow marks the two measuring points with the same SN, but different tumble. The smoke increases with high tumble; to keep smoke emissions low, the SN needs to be increased when the tumble is high. This trend is seen in all graphs. The 1500 bar and 2000 bar cases closely follow the same trend as the 1000 bar case. Higher injection pressure needs higher SN to achieve the lowest possible smoke. At 500 bar injection pressure, 'over-swirling' happens and diesel sprays start to interact with each other, 
increasing smoke levels.

The CO emissions are plotted in Figure 18 for the load point 1 . At 500 bar injection pressure the lowest $\mathrm{CO}$ emissions can be seen around the same SN where the smoke is at the lowest levels. At 1000 bar the area where low CO can be seen is larger, and at high SN the CO emissions increase. At higher injection pressure, the $\mathrm{CO}$ emissions are reduced (note the different colour scales between the graphs). A significant trend is difficult to define, but it seems that low SN gives high CO in the 2000 bar case. High CO
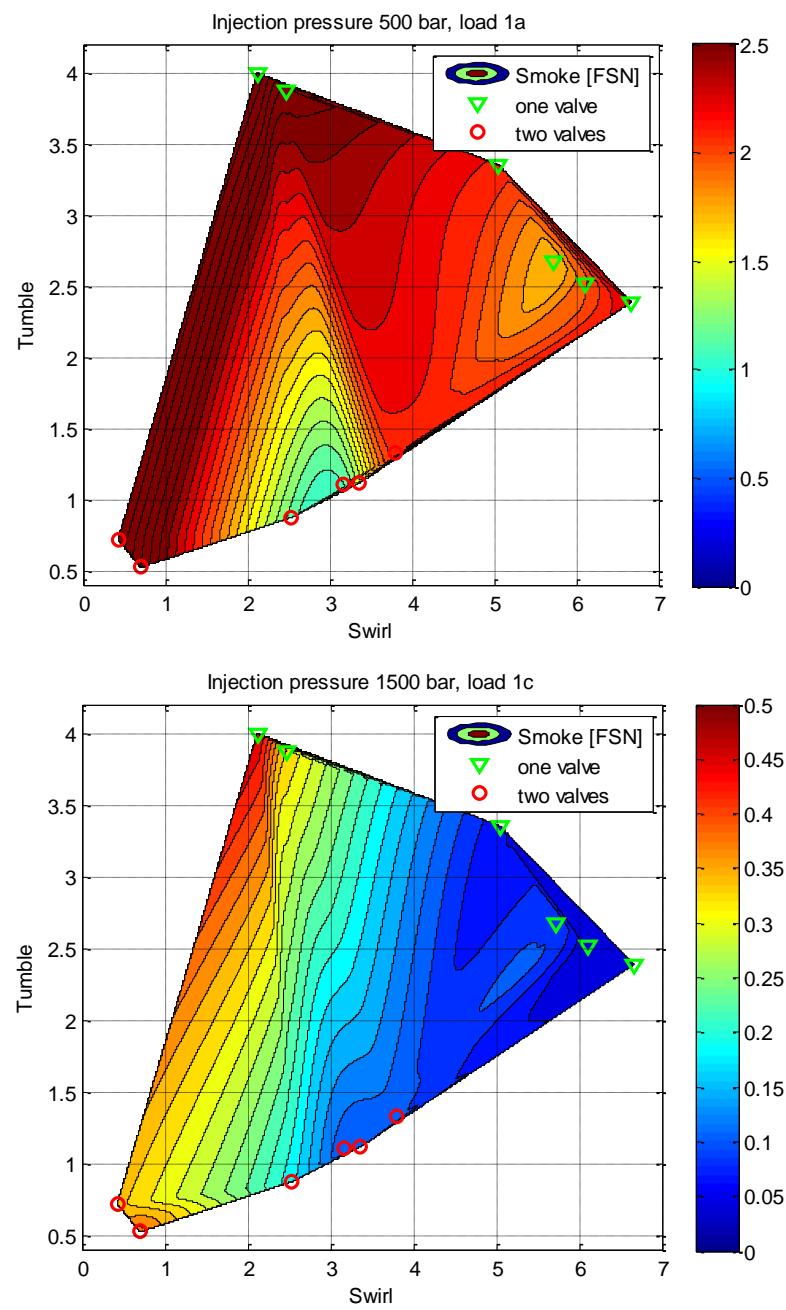

comes from incomplete combustion, lack of air, cold combustion, or a combination of these factors. Our results show that air penetrated the diesel spray at high SN (see also [28]). At low SN lack of air results in $\mathrm{CO}$ emissions; at very high SN incomplete combustion occurs when air penetrates and moves combustion products and fuel to the leeward side, where the temperature drops below the combustion plume. When this happens too quickly and with a temperature drop, for example at very high $\mathrm{SN}, \mathrm{CO}$ is not reduced in the latter part of combustion.
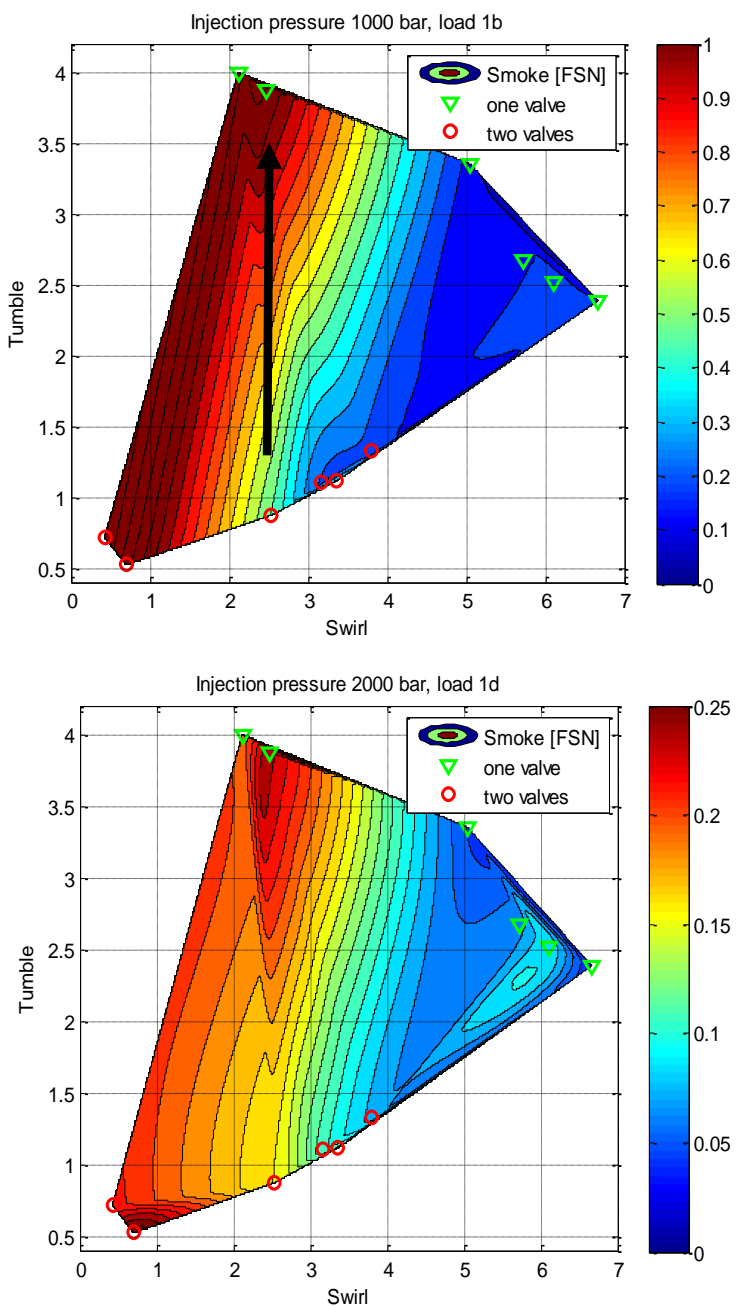

Figure 17 Smoke emissions for different injection pressures, at 10 bar IMEP, plotted against swirl and tumble. The tested valve settings are marked with red circles for two valves and with green triangles for one valve. 

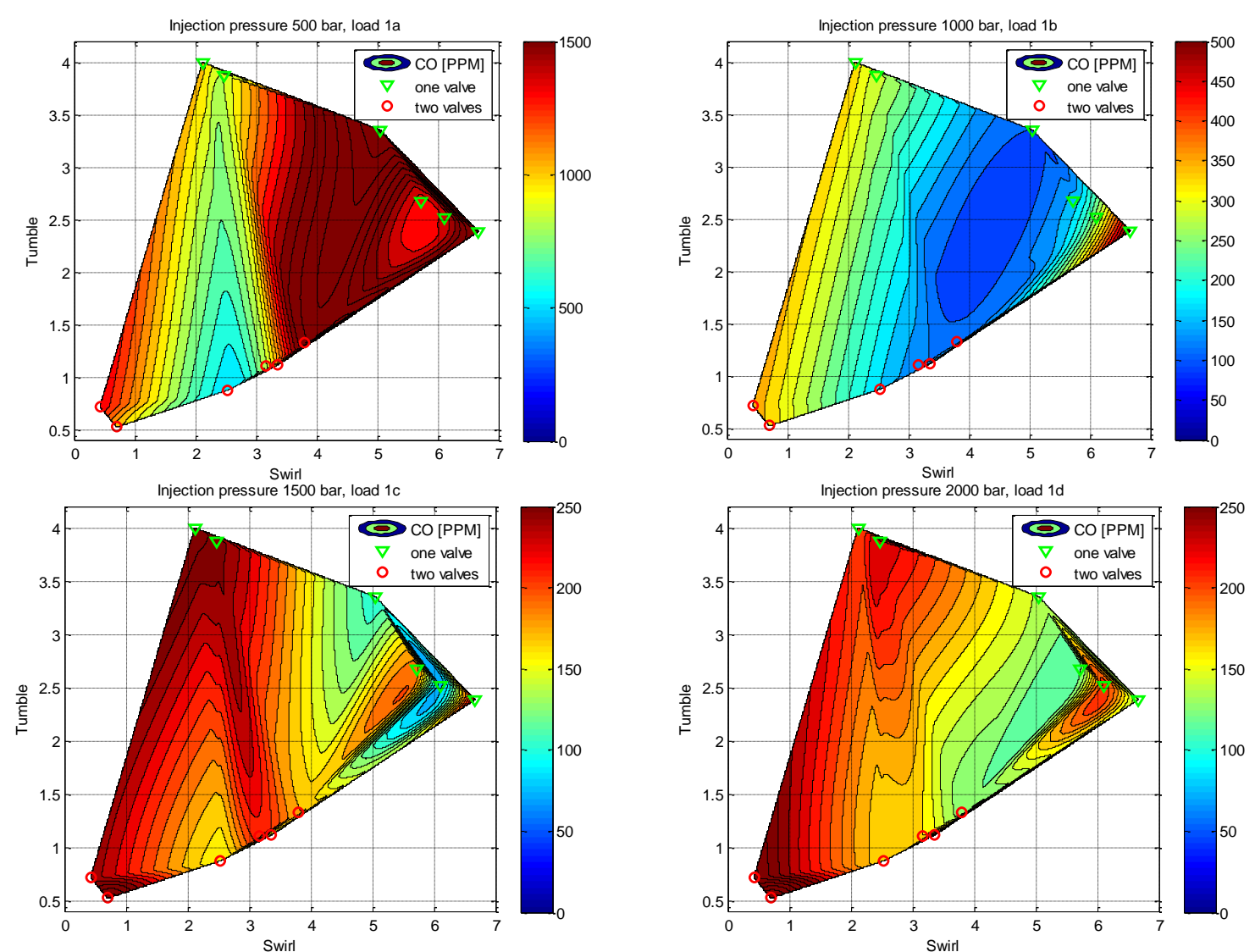

Figure 18. CO emissions at different injection pressures at 50\% load, 10 bar IMEP, plotted against swirl and tumble. 
High injection pressures result in high $\mathrm{NO}_{\mathrm{x}}$ emissions (see Figure 19) compare to low injection pressures. The shorter injection duration in the high injection pressure case, for equal amounts of fuel, results in fast combustion and high combustion temperature. At high SN, $\mathrm{NO}_{\mathrm{x}}$ and $\mathrm{CO}$ seem to be strongly associated. When high CO is observed in Figure 18 (at high $\mathrm{SN})$ the $\mathrm{NO}_{\mathrm{x}}$ in Figure 19, at the same load point,
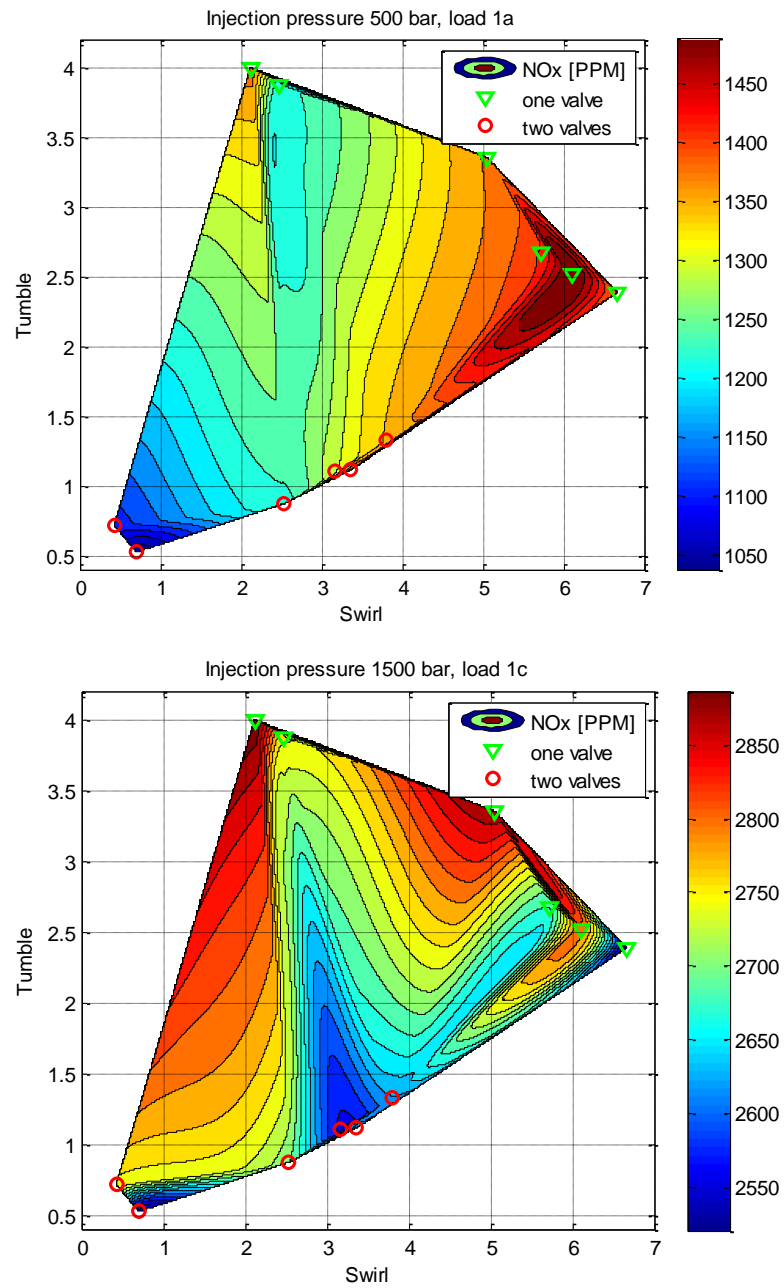

Figure $19 \mathrm{NO}_{\mathrm{x}}$ emissions for different injection pressures at $50 \%$ load, 10 bar IMEP, plotted against SN and tumble.

To better understand the emission behaviour during the very first part of the transient, when the $\lambda$ goes from high levels to the lowest value, a $\lambda$ sweep was done at two different swirl levels, shown as load point 2 in Table 1. Injection pressure was set to 2000 bar, engine speed 1000 rpm, SOI -2 degrees, inlet pressure 1.5 bar (abs), exhaust pressure 1 bar, and the injection duration was swept to reach different $\lambda$. In Figure 20 the emissions are plotted for different $\lambda$. The $\mathrm{NO}_{\mathrm{x}}$ emissions increase until $\lambda$ reach 1.4, where maximum $\mathrm{NO}_{\mathrm{x}}$ emissions are observed. For both tested swirl levels the HC emissions drop to very low values at low $\lambda$ (see the $\mathrm{HC}$ scale in Figure 20). HC is oxidized to $\mathrm{CO}$ and smoke at low $\lambda$ when the mean temperature in the cylinder is low. At high $\mathrm{SN}$ the $\mathrm{NO}_{\mathrm{x}}$ and $\mathrm{CO}$ emissions are sensitive for small changes in the flow field, and the combustion starts to become unstable. High CO signals incomplete combustion, while low $\mathrm{NO}_{\mathrm{x}}$ indicates bad combustion due to low temperature, as $\mathrm{NO}_{\mathrm{x}}$ formation is strongly influenced by temperature.
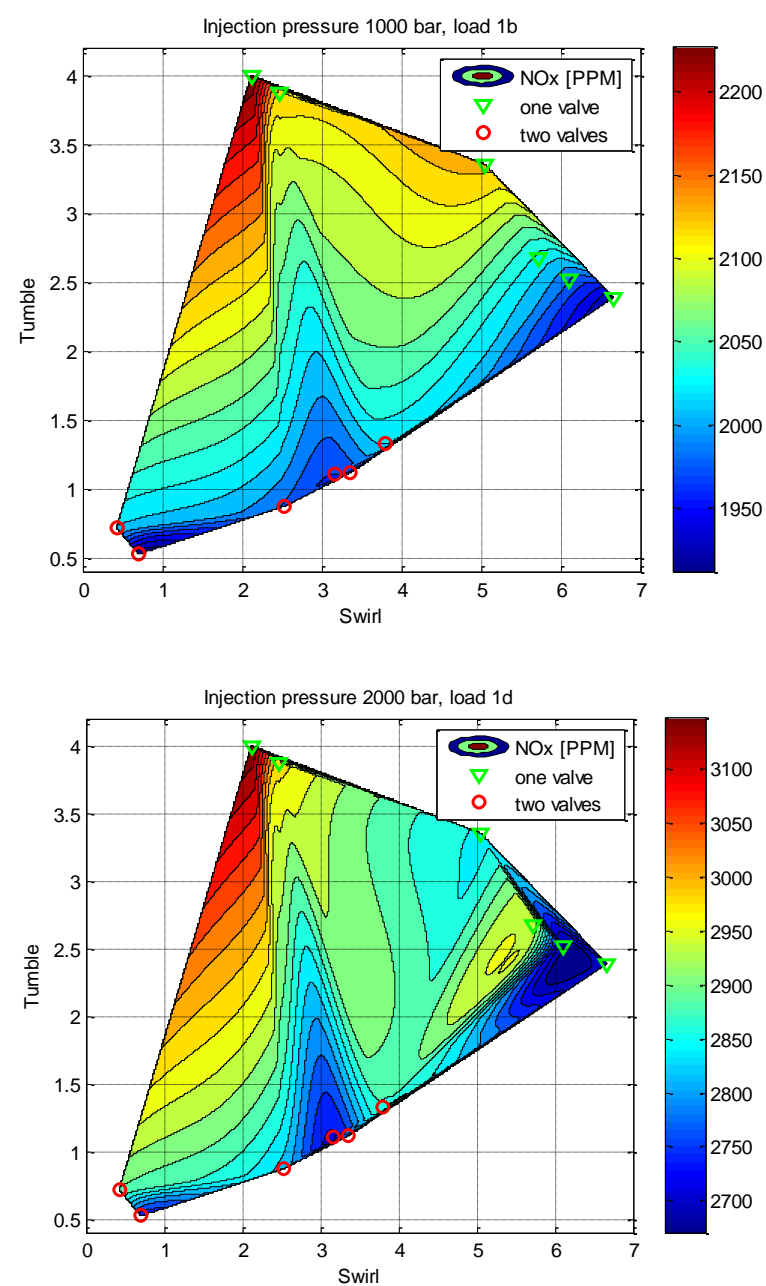
increases. 


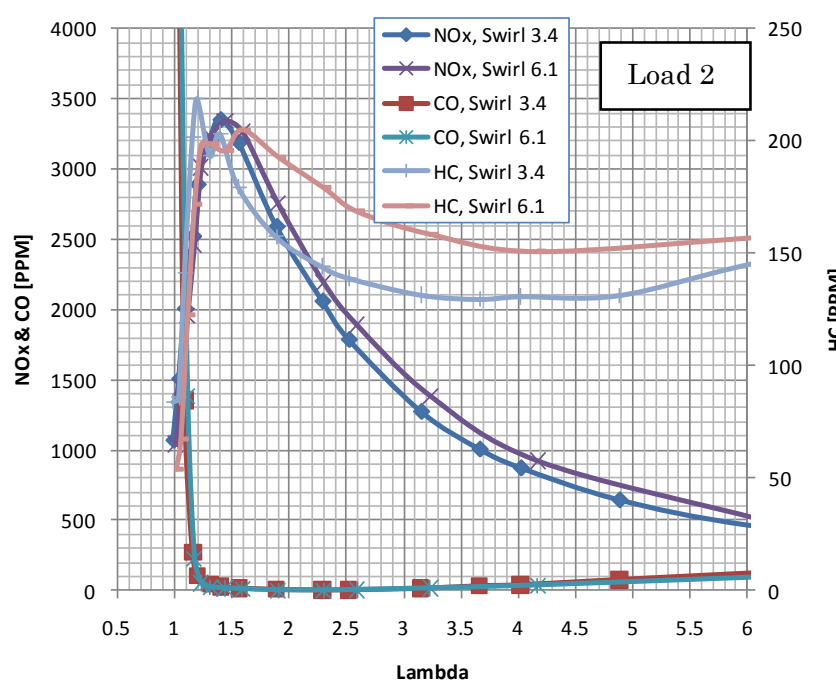

Figure 20 Emissions are plotted at constant inlet pressure and variation in $\lambda$ by different injection duration.

In Figure 21 smoke is plotted with $\mathrm{NO}_{\mathrm{x}}$ and $\mathrm{CO}$. $\mathrm{CO}$ emissions start to increase rapidly independent of the $\mathrm{SN}$, but the smoke starts to increase later for swirl at 6.1 with almost the same $\mathrm{NO}_{\mathrm{x}}$ levels in both cases. The $\mathrm{NO}_{\mathrm{x}} /$ smoke trade-off is thus moved in a delicate way. With swirl 3.4, $\lambda$ cannot be reduced below 1.2 without the smoke beginning to rise. With swirl $6.1, \lambda$ can reach 1.1 with maintained low smoke and a $\mathrm{NO}_{\mathrm{x}}$ level $900 \mathrm{ppm}$ lower than when the $\mathrm{SN}$ is 3.4.

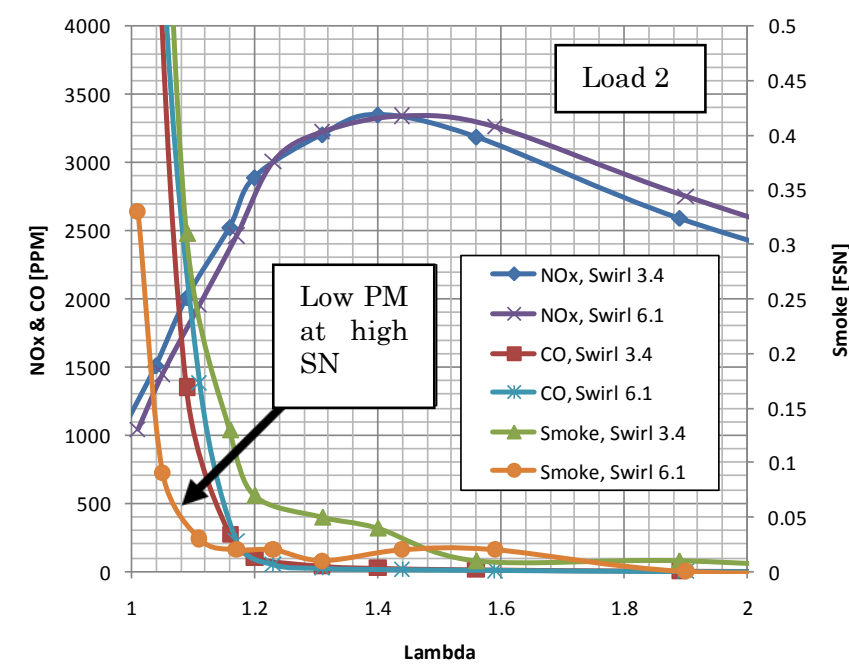

Figure 21 Emissions with constant inlet pressure as a function of $\lambda$ at SN 3.4 and SN 6.1.

\section{HIGH ENGINE SPEED}

In load point 3 , in Table 1 , an engine speed sweep was done from $800 \mathrm{rpm}$ to $2000 \mathrm{rpm}$ and 1500 bar injection pressure. The $\lambda$ was kept constant at 1.25 by varying the boost pressure. The crank angle at maximum cylinder pressure was set to $11 \mathrm{CAD}$ and held constant over the entire speed range. At higher engine speed the engine breathing starts to be a problem when only one inlet valve is used. The pumping losses increase at high SN when this costs energy to create. At high SN, which is reached by deactivating one valve, the smoke is higher than with low swirl at engine speeds higher than $1200 \mathrm{rpm}$ (see Figure 22). $\mathrm{NO}_{\mathrm{x}}$ emissions are higher with high swirl and decrease with higher engine speeds when the residence time at high temperature decreases. The combustion duration from MBF5\% to MBF50\% (plotted in ms) is lower with one valve than with two valves. This results in higher $\mathrm{NO}_{\mathrm{x}}$ emissions when energy is released more quickly, resulting in higher mean cylinder temperature. Combustion duration decreases with engine speed, since the air speed increases and thereby decreases the combustion duration time from MBF5\% to MBF50\%.

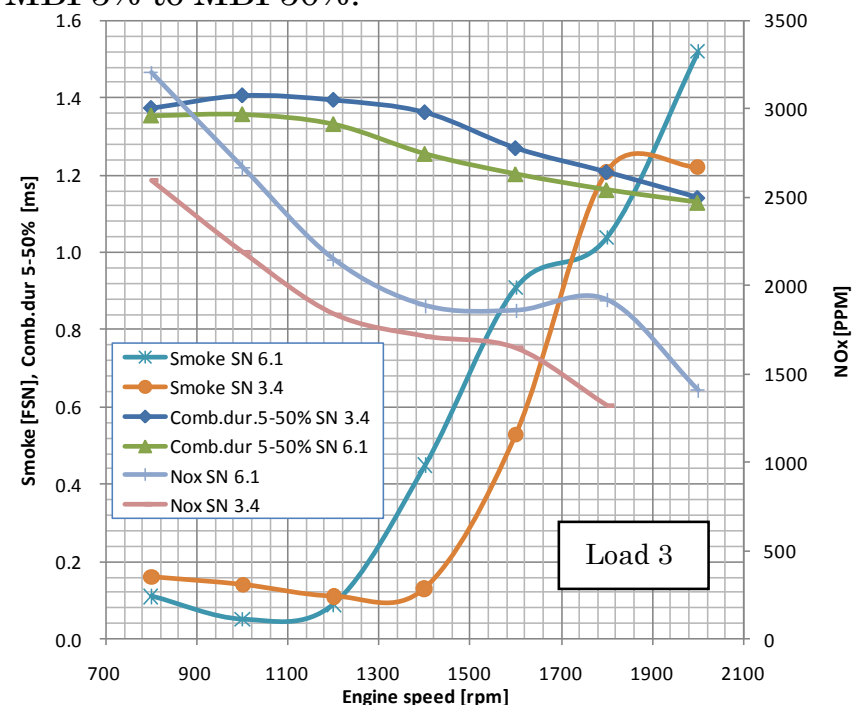

Figure 22 Smoke-, $\mathrm{NO}_{\mathbf{x}}$-emissions and combustion duration time from $5 \%$ to $50 \%$ as a function of engine speed.

\section{CONCLUSIONS}

1. Swirl: Injection pressure reduces smoke emissions efficiently, but swirl still influences smoke emissions strongly, even at 2000 bar injection pressure. Heat release is also affected by swirl for injection pressure at 2000 bar. Higher SN results in higher HR intensity during the diffusion combustion period and lower intensity during the after-oxidation period. At low $\lambda$ the $\mathrm{NO}_{x}$ is reduced. With higher $\mathrm{SN}, \lambda$ can be reduced with the same smoke emissions and reduced $\mathrm{NO}_{x}$ as a side effect.

2. Tumble: Tumble together with turbulent intensity created by the inlet-valves under inlet stroke affects the ignition delay. The turbulent intensity, created under the inlet stroke by the inlet valves, gives a higher cylinder pressure (higher cylinder temp at the same air flow when valve profiles changes to low lift) and thereby shorter ignition delay. But the change in measured ignition delay are not fully explained with Arrhenius correlation that take the cylinder pressure and temp into 
account. The tumble motion seems to have an effect on ignition delay also. The global tumble flow motion is transformed into small-scale turbulent intensity at the end of the compression due to the geometric change in the combustion chamber under compression. In a diesel engine the first added fuel burns premixed. If the turbulent intensity is increased, premixing time is shorter and the premixed mixture is more intensely mixed [27], which decreases the ignition delay. Tumble disturbs the swirl. Higher swirl is needed when high tumble is used to promote low smoke and $\mathrm{CO}$ emissions.

3. Higher engine speed increases the air speed in the cylinder when the $\mathrm{SN}$ is more or less constant over the engine speed range. This can result in problems at high engine speed due to over-swirling. The SN needs to be reduced at high engine speed to maintain low smoke emissions and low pumping losses.

\section{ACKNOWLEDGEMENTS}

This work was supported by the Swedish Energy Agency, Scania CV AB, and the Royal Institute of Technology (KTH Stockholm), with a special thanks to Per Risberg, Anders Björnsjö, Vladimir Milosavljevic and Jonas Holmborn.

\section{REFERENCES}

1. Alberer, Daniel; del Re, Luigi. On-line Abatement of Transient NOx and PM Diesel Engine Emissions by Oxygen Based Optimal Control. SAE paper 2010-01-2201.

2. Tufail, K.; Winstanley, T.; Karagiorgis, S.; Hardalupas, Y.; Taylor, M. K. P. Characterisation of Diesel Engine Transient Pumping-loss and Control Methodology for Transient Specific Fuel Consumption (SFC). SAE paper 2009-01-2748.

3. Kirchen, Patrick; Obrecht, Peter; Boulouchos, Konstantinos. Soot Emission Measurements and Validation of a Mean Value Soot Model for Common-Rail Diesel Engines during Transient Operation. SAE paper 2009-01-1904.

4. Darlington, Alex; Glover, Keith; Collings, Nick. A Simple Diesel Engine Air-Path Model to Predict the Cylinder Charge During Transients: Strategies for Reducing Transient Emissions Spikes. SAE paper 2006-01-3373.

5. Schwoerer, John; Kumar, Krishna; Ruggiero, Brian; Swanbon, Bruce. Lost-Motion VVA Systems for Enabling Next-Generation Diesel Engine Efficiency and After-Treatment Optimization. SAE paper 2010-01-1189.

6. Deng, Jiamei; Stobart, Richard. BSFC Investigation Using Variable Valve Timing in a Heavy Duty Diesel Engine. SAE paper 2009-01-15-25.

7. Suzuki, Takashi. The Romance of Engines. 1997. ISBN 1-56091-911-6.
8. Antila, Eero; Imperato, Matteo; Kaario, Ossi; Larmi, Martti. Effect on Intake Channel Design to Cylinder Charge and Initial Swirl. SAE paper 2010-01-0624.

9. Genzale, Caroline L.; Reitz, Rolf D.; Wickman, David D. A Computational Investigation into the Effects of Spray Targeting, Bowl Geometry and Swirl Ratio for Low-Temperature Combustion in a Heavy-Duty Diesel Engine. SAE paper 2007-01-0119.

10. Group Lotus PLC, Lotus Engineering. Standard AVT ${ }^{\mathrm{TM}}$ Package. 2011. Available at: http://www.lotuscars.com/engineering/en/avt-sta ndard-package.

11. Dembinski, Henrik; Lewis, Clive. Miller-cycle on heavy duty diesel engines. Stockholm: KTH, 2009. Master's Thesis, MMK2 2009:1 MFM124.

12. Thien G. E. Entwicklungsarbeiten an Ventilkanälen von Viertakt-Dieselmotoren. (Valve Port Development of Four-Stroke Diesel Engines) - Graz: Österreichische Ingenieurzeitschrift, 1965, Vol. 9.

13. Stone, C. R.; Ladommatos, N. The Measurement and Analysis of Swirl in Steady Flow. SAE paper 921642 .

14. Stephenson, P.; Rutland, C. Modeling the Effects of Valve Lift Profile on Intake Flow and Emissions Behavior in a DI Diesel Engnie. SAEpaper 952430.

15. Morel, T.; Rackmil, I.; Keribar, R.; Jennings, M. J. Model for Heat Transfer and Combustion in Spark Ignited Engines and Its Comparison with Experiments. SAE paper 880198.

16. Uzkan, Teoman; Borgnakke, Claus; Morel, Thomas. Characterization of Flow Produced by High-Swirl Inlet Port. SAE paper 830266.

17. Morel, Thomas; Keribar, Rifat. A Model for Predicting Spatially and Time Resolved Convective Heat Transfer in Bowl-in-Pistin Combustion Chambers. SAE paper 850204.

18. Nordgren, Henrik; Hildingsson, Leif; Johansson, Bengt; Dahlén, Lars; Konstanzer, Dennis. Comparison Between In-Cylinder PIV Measurements, CFD Simulations and Steady-Flow Impulse Torque Swirl Meter Measurements. SAE paper 2003-01-3147.

19. Reuss, David L. Cyclic Variability of Large-Scale Turbulent Structures in Directed and Undirected IC Engine Flows. SAE paper 2000-01-0246.

20. Yu, R. U.; Bai, X. S.; Hildingsson, L.; Hultqvist, A.; Miles, P. Numerical and experimental investigation of turbulent flows in a diesel engine. SAE paper 2006-01-3436.

21. Lindström, Mikael; Ångström, Hans-Erik. A Study of In-Cylinder Fuel Spray Formation and its Influence on Exhaust Emissions Using an Optical Diesel Engine. SAE paper 2010-01-1498.

22. Shimoda, Masatoshi; Shigemori, Masashi; 
Tsuruoka, Shingo. Effect on Combustion Chamber Configuration on In-Cylinder Air Motion and Combustion Characteristics of D.I. Diesel Engine. SAE paper 850070.

23. Shigemori, Masashi; Tsuruoka, Shingo; Shimoda, Masatoshi. Development of a Combustion System for a Light Duty D.I. Diesel Engine. SAE paper 831296.

24. Shiozaki, T; Suzuki, T; Shimoda, M. Observation of Combustion Process in D.I. Diesel Engine via High Speed Direct and Schlieren Photography. SAE paper 800025.

25. Suzuki, Takashi; Shiozaki, Tadakazu. A New Combustion System for the Diesel Engine and Its Analysis via High Speed Photography. SAE paper 770674.

26. Heywood, John B. Internal Combustion Engine Fundamentals (international edition). 1988. ISBN: 0-07-100499-8.

27. Beér, J. M.; Chigier, N. A. Combustion Aerodynamics. London: Applied Science, 1972.

28. Reitz, Rolf D; Bergin, Michael J; Oh, Seungmook; Miles, Paul C; Hildingsson, Leif; Hultqvist, Anders. Fuel Injection and Mean Swirl Effects on Combustion and Soot Formation in Heavy Duty Diesel Engines. SAE paper 2007-01-0912.

\section{CONTACT}

Henrik Dembinski M.Sc.

Scania CV AB

Telephone: +46 (0)8 55380769

Fax: +46 (0)855381005

Mail: henrik.dembinski@scania.com

Postal address: SE-151 87 Södertälje, Sweden

\section{DEFINITIONS, ACRONYMS, ABBREVIATIONS}

ATDC $=$ after top dead centre

$\mathrm{BDC}=$ bottom dead centre

$\mathrm{CAD}=$ crank angle degrees

$\mathrm{CO}=$ carbon monoxide

EGR = exhaust gas recirculation

$\mathrm{HC}=$ hydrocarbon

$\mathrm{HR}=$ heat release

IMEP = indicated mean effective pressure (over the entire engine cycle, $720^{\circ} \mathrm{CAD}$ )

IVC $=$ inlet valve closed

$\mathrm{MBF}=$ mass burned fraction

$\mathrm{NOx}=$ nitrogen oxide $\left(\mathrm{NO}\right.$ and $\left.\mathrm{NO}_{2}\right)$

$\mathrm{PM}=$ particulate matter

$\mathrm{SN}=$ swirl number, (Air rpm at BDC/crank shaft rpm)

$\mathrm{SN}_{\mathrm{T}}=$ swirl number $($ Thien definition [12])

$\mathrm{SOC}=$ start of combustion

$\mathrm{SOI}=$ start of injection

Std $=$ standard valve profile

$\mathrm{TDC}=$ top dead centre
$\mathrm{TF}=$ tumble flow

Trap = trapezoid valve profile

WHSC $=$ World Harmonized Stationary Cycle WHTC $=$ Word Harmonized Transient Cycle $\lambda=$ Air/fuel ratio 
16 (16) 